\title{
PANORAMA DA EDUCAÇÃO AMBIENTAL NAS ESCOLAS PÚBLICAS
}

\author{
Julio Cesar Voltani ${ }^{1}$, Roberta Maria Salvador Navarro ${ }^{2}$ \\ ${ }^{1}$ Pós-graduando do curso de MBA Gestão Ambiental (ju.ces@bol.com.br) \\ ${ }^{2}$ Professora orientadora
}

\section{RESUMO}

O presente artigo pretende analisar os caminhos da Educação Ambiental (EA) no Ensino nas Escolas Públicas. Contribuir com os estudos relacionados ao tratamento de questões ambientais nas escolas. Mostrar que a Educação Ambiental nos Parâmetros Curriculares Nacionais (PCN) é um dos temas transversais deve estar presente em todas as disciplinas, devido a sua importante relevância no mundo atual deveria ser tratada com uma disciplina única nas escolas. Levando ao educando todas as formações e informações sobre Educação Ambiental.

A proposta educativa deste artigo, é a formação de jovens e adultos com capacidade de compreender um mundo em constante transformação. Onde o projeto político-pedagógicoda Educação Ambiental pode ser descrito como a formação do individuo capaz de "ler" e "interpretar"de forma critica as relações, os conflitos e os problemas presentes no seu ambiente e no nosso planeta.

A analise crítica das questões ambientais e a necessidade de compreensão do lugar ocupado pelo individuo são os pontos de partida para exerce uma consciência de cidadania ambiental.

PALAVRAS-CHAVE: Educação Ambiental, Escolas, Interdisciplinaridade, Sustentabilidade, PCN e LDB 9394/96.

\section{ABSTRACT}

The article analyzes the ways of teaching environmental education in schools. Helping with the studies related to the treatment of environmental issues in schools. Show that the Environmental Education in National Curriculum Parameters (PCN) is cross-cutting themes should be present in all subjects, due to its important relevance in today's world should be treated with a single discipline in schools. Taking all the training and educating about environmental education.

The educational approach of this article is the formation of young and adults with ability to understand a changing world. Where the project political and pedagogical teaching environmental education can be described as the formation of the subject can "read" and "interpret" a critical relationships, conflicts and problems in your environment and our planet.

The critical analysis of environmental issues and the need for understanding the place occupied by the subject are the starting points for exercising an awareness of environmental citizenship. 


\section{INTRODUÇÃO}

A frase a seguir em cita a essência da Educação Ambiental concreta e contínua, evidencia de forma clara a importância da preservação do meio ambiente para a continuidade de nossas vidas e a educação que deixaremos as próximas gerações para se viver em um lugar melhor.

"Todo mundo 'pensando' em deixar um planeta melhor para nossos filhos... Quando é que 'pensarão' em deixar filhos melhores para o nosso planeta?" (autor desconhecido)

A educação ambiental nos Parâmetros Curriculares Nacionais (PCN) é um dos temas transversais, e deve ser trabalhada enfatizando-se os aspectos sociais, econômicos, políticos e ecológicos. As vantagens de uma abordagem assim é a possibilidade de uma visão mais integradora e melhora na compreensão das questões socioambientais como um todo. Logo, como tema transversal ou tema interdisciplinar, a Educação Ambiental deve estar presente em todas as disciplinas, perpassando seus conteúdos, como é desejado pelos educadores ambientais .

Ao mesmo tempo a Educação Ambiental tem a chance de estar presente em todas as disciplinas, um tema transversal não possui um "status" de ser uma disciplina única, sendo muitas vezes deixada em segundo plano em relação aos conteúdos disciplinares. A proposta dos PCNs é de uma abordagem ambiental integrada, tanto entre as disciplinas como entre a sociedade seus problemas específicos.

A necessidade de se tratar da Educação Ambiental nas escolas com disciplina única, devido esta questão já estar em inserida na sociedade, onde o ser humano é agente deste contexto e que sua postura frente a ele pode agravar ou mudar o rumo de suas vidas e de planeta. Melhorando a qualidade vida e das espécies, e lembrando que ele é um hospede e esta de passagem por esse grande planeta Terra.

Acredito que deveria uma nova postura da administração escolar, acrescentando em sua grade escolar uma disciplina específica a Educação Ambiental voltada para proteção do meio ambiente, cujo embasamento teórico propicia compreender os modelos de gestão direcionados à sustentabilidade.

As grandes modificações globais e a modernização nos tempos atuais. Apresenta aspectos históricos, que a falta de discussões sobre o meio ambiente e os impactos ambientais estão degradando cada vez mais nosso planeta.

Analisar os caminhos de uma nova postura em relação ao meio ambiente e a uma educação concreta e continua, voltada para proteção do meio ambiente, uso dos recursos não renováveis, e à sustentabilidade. 
"Paulo Freire, pelos anos de 1980 e 1981 em sua linha de pensamento já estava preocupado com relação Educação Ambiental discutida até hoje, após 30 anos."

Ele expõe seus pensamentos da seguinte forma, por que não aproveitar a experiência que têm os alunos de viver em áreas da cidade descuidadas pelo poder público para discutir, por exemplo, a poluição dos riachos e dos córregos e os baixos níveis de bem-estar das populações, os lixões e os riscos que oferecem à saúde das gentes. Por que não há lixões no coração dos bairros ricos e mesmo puramente remediados dos centros urbanos.

Nos seus livros Paulo Freire reflete sobre saberes necessários à prática educativa fundamentada numa ética pedagógica e uma visão de mundo alicerçadas em rigorosidade, pesquisa, criticidade, risco, humildade, bom senso, tolerância, alegria, curiosidade, esperança, competência, generosidade, disponibilidade... molhadas pela esperança. Autonomia que faz da própria natureza educativa.

Figura 1- Ilustração da Educação Ambiental Brasileira

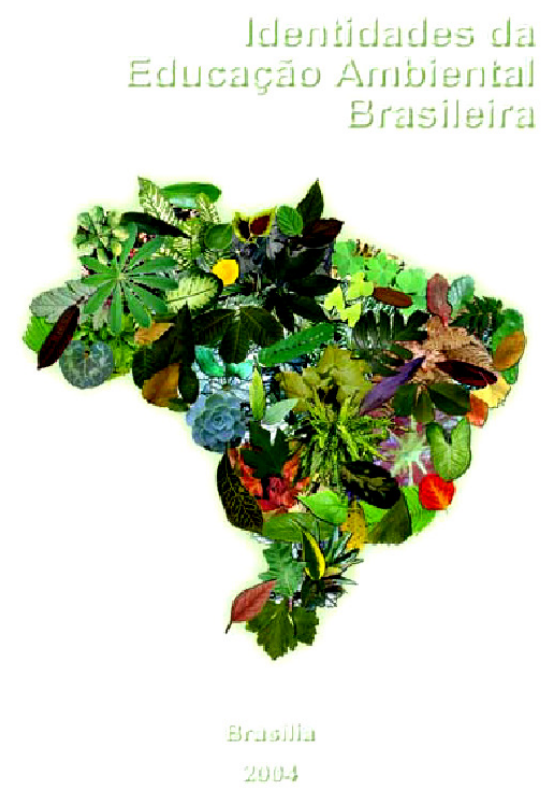

Fonte: Ministério do Meio Ambiente - MMA - acesso 24/11/2011

Centro de Informação, Documentação Ambiental e Editoração

http://www.mma.gov.br/port/sdi/ea/og/pog/arqs/livro ieab.pdf 


\section{METODOLOGIA}

A metodologia aplicada na elaboração deste artigo baseou-se na experiência profissional do autor, assim com a pesquisa de publicações e temas sobre o assunto. Inicialmente foi estudado o tema Educação Ambiental, as leis e normas que abrangem o tema em nosso país, assim com a sua necessidade real da prática, já que compromete diretamente a vida de cada um de nós. Existem várias discussão e reflexão sobre educação ambiental, mas procurei abordar o tema aqui de uma forma genérica e que fosse possível assimilar todos os processos envolvidos, visando uma fácil compreensão do assunto e sua importância pelo leitor.

O tema escolhido reflete a constante presença da problemática ambiental nas discussões que se realizam nos meios de comunicação, na comunidade científica e também no cotidiano do professor em sala de aula, através dos temas transversais (interdisciplinaridade) propostos nos PCN. Dentre estes se encontra o "meio ambiente", o qual busca possíveis caminhos para o enfrentamento da problemática ambiental atual.

Um dos objetivos deste artigo é analisar os Parâmetros Curriculares Nacionais (PCN), bem como a disposição da problemática educação ambiental no documento com um tema transversal ou interdisciplinaridade e não uma disciplina única.

Para tanto, utilizei como metodologia a pesquisa teórico-bibliográfica e estruturei o em artigo seções:

1. O Movimento Ecológico no Brasil

2. OS Parâmetros Curriculares Nacionais (PCN)- 1997 a 2012 - 15 anos;

3. Lei No9.9394/96, (LDB), Lei De Diretrizes e Bases.

4. Os PCN e a Questão Ambiental

5. Educação Ambiental: Resíduos Domésticos e Cidadania - Uma lição de vida.

6- A Reciclagem no Brasil

\section{Desenvolvimento}

As idéias que nos passam é que os professores ao trabalharem os temas abordados na Educação Ambiental, consiste em atividades esporádicas e superficiais, muitas vezes restritas às disciplinas de Geografia e Ciências e Biologia. As principais dificuldades dos professores dizem respeito às questões orçamentárias e estruturais, como, também, à motivação, capacitação e compreensão do tema, além de dificuldades de relacionamento entre si e em liderar projetos e comprometer-se com o seu andamento.

A ação para fazer a reciclagem do lixo, pode colocar um ponto de interrogação em uma sala de aula. Alguns podem entender que esta correta à forma que as pessoas colocam em saco de lixo latas papel e em outro resto de comida e qualquer outro lixo. Isso faz parte do cotidiano do sujeito à ação correta de separação, enquanto outros não se importam. Por esses e outros motivos, o papel do educador é fundamental na mudança desses sujeitos, mostrando que a reciclagem na sua casa é importante e fundamental para construir idéias de convivência amistosa, respeitosa e prudente com o meio ambiente, tornando esse sujeito corretamente ecológico.

O livro didático tem grande influência sobre o tipo de aula que acontece nas escolas, Às vezes tirando até mesmo, a autonomia dos professores e alunos sobre discussões e aprendizado. Pegando como exemplos livros didáticos atuais de Ciências do Ensino Fundamental II. Noto 
avanços nos temas didáticos e preocupação com os temas transversais e conseqüente contextualização dos conteúdos abordados. Porém, permanece a tradicional sequência de conteúdos: estudo do meio para os 60 anos, seres vivos para os 70 anos, corpo humano para os 8 응

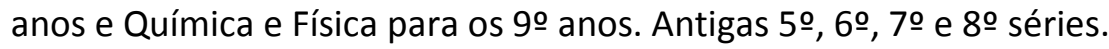

Havendo uma diferenciação em que os PCN (Parâmetros Curriculares Nacionais) propõem a divisão em quatro eixos, Terra e Universo; Vida e Ambiente: Ser Humano e Saúde; Tecnologia e Sociedade, além dos temas transversais. Para isso, sugerem a tematização dos conteúdos.

A Educação Ambiental é um processo de humanização que ocorre na sociedade, para mostra a importância deste sujeito no processo civilizatório e responsável, sendo individual ou coletivo, onde devemos preservar para continuar a viver.

\section{1- O MOVIMENTO ECOLÓGICO NO BRASIL}

- "É Proibido, proibir"

Uma síntese sobre o movimento ecológico no Brasil, a década de 70 do século passado tem o marco de luta democrática em contextos de governos autoritários, onde o slogan "Proibido Proibir", levanta e leva os problemas para esfera pública. E um dos temas abordado é ecologia, onde se faz referencia ao estilo de vida, denunciando sua face materialista,, agressora ao meio ambiente. Contudo não há grandes avanços na idéia ambiental. No Brasil a Educação Ambiental aparece na legislação desde 1973, como atribuição da primeira Secretaria Especial do Meio Ambiente (SEMA)

Na década de 80 , o processo de redemocratização e abertura política, entra em cenas os novos movimentos sociais e o tema ecologia volta, com as características contestatórias. A nova ordem econômica chama a atenção para os impactos ambientais. E a pressão da produção para a liberação de sementes transgênicas no Brasil.

A educação Ambiental é parte desse movimento ecológico, estimulando conferência e seminários internacionais e nacionais.

No Brasil só nas décadas de 80 e 90, com o avanço da consciência ambiental, que a Educação Ambiental cresce e se torna mais conhecida.

\section{Os Parâmetros Curriculares Nacionais}

Os Parâmetros Curriculares Nacionais (PCN) constituem um conjunto de documentos

Que desde 1997 foi implementado em todo o território nacional como referência de renovação e reelaborarão da proposta curricular. A reforma educacional brasileira, encaminhada sob a coordenação do MEC apartes dos anos 1990, lança um programa de universalização da educação básica, investindo num material de trabalho para orientar os professores diretamente no que se refere aos conteúdos e práticas em sala de aula: os Parâmetros Curriculares Nacionais do Ensino Fundamental, parâmetros para a Educação Infantil, a Educação de Jovens e Adultos e o Ensino Médio. 
De modo geral, os PCN estruturam-se em documentos que abordam os conteúdos das diferentes áreas do conhecimento, ou seja, do ensino fundamental ao médio deve-se estudar língua portuguesa, matemática, o mundo físico e natural, a realidade social e política, enfatizando se a situação brasileira. São entendidas também, como áreas obrigatórias, a Arte e a Educação Física. O ensino de ao menos uma língua estrangeira moderna passa a se constituir um componente curricular obrigatório, a partir d sexto ano do ensino fundamental.

Compõem os PCN, também, documentos referentes aos temas transversais ou temas interdisciplinares. São a ética, a saúde, o meio-ambiente, a orientação sexual e a pluralidade cultural foram incorporados a fim de cumprir o compromisso social de construção da cidadania a partir da compreensão da realidade social e dos direitos e responsabilidades em relação à vida pessoal, coletiva e ambiental. No entanto, estes temas não devem ser entendidos como novas disciplinas, mas abordados de forma integrada entre as diferentes áreas.

\section{- Política Nacional garante Educação Ambiental}

Em 27 de abril de 1999 foi sancionada a lei n.o 9.795, que instituiu a Política Nacional para garantir que a Educação Ambiental seja uma prática nacional em todas as escolas. Foi criado também o PCN em ação - Educação Ambiental, guia de orientações metodológicas desenvolvido para formação de educadores, além de projetos e programas que visam construir um processo permanente de educação ambiental nas escolas e comunidades de todo Brasil. Mesmo assim a Educação Ambiental Continua com "status" de temas transversais e Não uma disciplina única.

\section{LEI DE DIRETRIZES E BASES DA EDUCAÇÃO NACIONAL (LDB)}

A aprovação da LDB, Lei de Diretrizes e Bases da Educação Nacional (Lei Federal n. 9.394), em 1996. "Art. 1० A educação abrange os processos formativos que se desenvolvem na vida familiar, na convivência humana, no trabalho, nas instituições de ensino e pesquisa, nos movimentos sociais e organizações da sociedade civil e nas manifestações culturais.

$\S 1$ 을 Esta lei disciplina a educação escolar, predominantemente, por meio do ensino, em instituições próprias.

$\S 2$ 을 educação escolar deverá vincular-se ao mundo do trabalho e a pratica social.

- "Todo cidadão tem direito ao meio ambiente ecologicamente equilibrado, bem como o uso comum do povo e essencial à sadia qualidade de vida, impondo-se ao poder público e a coletividade o dever de defendê-lo e preservá-lo para presentes e futuras gerações"

- (Art. 225 da Constituição da República Federativa do Brasil) 
No que diz respeito à educação ambiental, outro foi o tratamento conferido pela Constituição. No artigo 225 está garantido o direito ao meio ambiente ecologicamente equilibrado, bem de uso comum do povo e essencial à sadia qualidade de vida. A par de conferir o direito, tratou a Lei Maior de impor ao Poder Público e à coletividade o dever de defendê-lo e preservá-lo para os presentes e futuras gerações. Tão relevante é esse tema que a Constituição traz algumas incumbências ao Poder Público no sentido de assegurar a efetividade do direito ao meio ambiente ecologicamente equilibrado, dentre as quais se encontra a de promover a educação ambiental em todos os níveis de ensino e a conscientização pública para a preservação do meio ambiente (inc. VI do art. 225 da CF).

Regulamentando essa incumbência do Poder Público está a Lei n. 9.795, de 27 de abril de 1999, com o Decreto n. 4.281, de 25 de junho de 2002. A leitura dessas normas deixa claro que a educação ambiental é um componente essencial e permanente da educação nacional, com presença de forma articulada em todos os níveis e modalidades do processo educativo, seja em caráter formal ou não-formal. No inciso I do artigo 3ㅇda Lei de Educação Ambiental está definida a incumbência ao Poder Público de definir as políticas públicas que incorporem a dimensão ambiental, promovendo-a em todos os níveis de ensino e o engajamento da sociedade na preservação, recuperação e melhoria do meio ambiente. Relevante mostrar que o artigo 9 dessa lei fixa o entendimento sobre o que seja a educação formal - é dizer - educação básica (infantil fundamental e média); educação superior; educação especial; educação profissional; educação de jovens e adultos. Antes dela, a LDB já disciplinava o que se deve entender por cada uma das modalidades, começando pelo artigo 21 (educação básica), desdobrada no artigo 29 (educação infantil), artigo 32 (ensino fundamental), artigo 35 (ensino médio), artigo 37 (educação de jovens e adultos), artigo 39 (educação profissional), artigo 43 (educação superior) e, finalmente, artigo 58 (educação especial). Nota-se, portanto, uma sensível ligação entre as duas normas, como não poderia deixar de ser, na medida em que ambas tratam de um só tema: a educação.

\section{Os PCN e a Questão Ambiental}

Educação Ambiental no Brasil, que foi assumida como obrigação nacional pela Constituição promulgada em 1988. Os Parâmetros curriculares nacionais resultam de um contexto sócioeconômico e histórico e, partindo das discussões globais a respeito das questões ambientais também apresenta o que é Educação Ambiental e sustentabilidade, bem como a importância de ambas na no mundo atual.

Verifica-se, assim, que as idéias defendidas por muitos movimentos, encontros e documentos, que tratam da importância da Educação Ambiental como forma de mobilização frente à degradação ambiental também se expressam nos PCN.

Os Paramentos Curriculares Nacionais "Trata-se de um princípio ético que 'reflete o dever de nos preocuparmos com as outras pessoas e outras formas de vida, agora e no futuro". São apresentados, também, quatro critérios de sustentabilidade: 1- melhorar a qualidade da vida Programa das Nações Unidas para o Meio Ambiente e Desenvolvimento. 2- conservar a vitalidade e a diversidade do Planeta Terra; 3- minimizar o esgotamento de recursos não renováveis; e 4- 
permanecer nos limites de capacidade de suporte do Planeta Terra. Dos quatro critérios, o primeiro é entendido como "o verdadeiro objetivo do desenvolvimento, ao qual o crescimento econômico deve estar sujeito: permitir aos seres humanos 'perceber o seu potencial, obter autoconfiança e uma vida plena de dignidade e "satisfação'." Finalizando a explanação que é feita a respeito do conceito de sustentabilidade nos documentos são verificados quatro meios para se chegar à sustentabilidade: 1- modificar atitudes e práticas pessoais; 2- permitir que as comunidades cuidem de seu próprio ambiente; 3- gerar uma estrutura nacional para a integração de desenvolvimento e conservação; e, 4- construir uma aliança global. Destes, no que se refere à mudança de atitudes e práticas pessoais, os PCN explicitam "Para adotar a ética de se viver sustentavelmente, as pessoas devem reexaminar os seus valores e alterar o seu comportamento". Entende-se que a educação ambiental é instrumento frente à problemática ambiental atual e que se busca, com ela, sustentabilidade. Esta idéia na educação brasileira esta presente na LDB (9394/96) e com os PCN.

\section{Educação Ambiental: Resíduos Domésticos e Cidadania - Uma lição para vida}

A quantidade de resíduos sólidos gerado por uma população releva sua classe social, com maior poder aquisitivo ou não, e a composição desses resíduos demonstra seus hábitos de consumo, e mostram também sua consciência política ambiental individual e coletivamente.

Nos últimos anos a composição desses resíduos vem se alterando. Cada vez mais produzem "materiais recicláveis" que, na maioria das vezes, não se degradam naturalmente e muitas vezes manejados de forma inadequada, não podendo ser reutilizadas e nem recicladas, acaba sendo queimadas em incineradores, gerando substâncias tóxicas e poluindo mais o ar.

No Brasil, há um grande percentual de resíduos sólidos, líquidos e pastosos, que nos lixões, entra em rápida decomposição, gerando gases e líquidos contaminados.

Na cidade de São Paulo a prefeitura interditou o Shopping Center Norte por risco de explosão. O terreno está contaminado com gás metano e pode explodir. No local funcionava um lixão e com o tempo, o material orgânico jogado ali liberou o gás.

O gás encontrado vem dos resíduos depositados no terreno que nas décadas anteriores o local abrigava um "grande lixão" a céu aberto. A decomposição dos produtos gerou o gás metano, que não tem cheiro e não é tóxico, mas é inflamável e pode explodir. A prefeitura da cidade São Paulo e a CETESB (Companhia Ambiental do Estado de São Paulo) reabriram o Shopping Center Norte informou que os resultados das ultimas vistorias "que permitem constatar que a operação dos drenos gerou pressão negativa no interior de grande parte dos poços situados nas imediações dos drenos, condição necessária para se prevenir a migração de gases para o interior do edifício". Dessa forma, não existiria o risco de explosão

No Estado de São Paulo existem outros milhares de terrenos na mesma situação. $O$ trabalho é das construtoras que antes de começar um empreendimento precisam fazer uma averiguação da área, para depois não passar por problemas de contaminação. 
A cidade de São Paulo gera 15 mil toneladas de lixo diariamente. Só de resíduos domiciliares são coletadas mais de 9,5 mil toneladas por dia. Estima-se que mais de 11 milhões de pessoas são beneficiadas pela coleta. O aterro sanitário Bandeirantes está desativado desde o mês de março de 2007, mas tem captação de gás. O material coletado pela concessionária é levado para o aterro de Caieiras. $O$ aterro São João está recebendo, parcialmente, os resíduos coletados pela Ecourbis. A outra parte está sendo levada para o CDR Pedreira (aterro que é particular).

No Brasil todo esse lixo gerado tem um destino, ou seja: $76 \%$ do lixo coletado no país ficam a céu aberto, ou seja, 182400 toneladas que é coletado por dia. O restante vai para aterros (controlados, $13 \%$; ou sanitários, $10 \%)$, usinas de compostagem $(0,9 \%)$, incineradores $(0,1 \%)$ e uma insignificante parte é recuperada em centrais de reciclagem. Estima-se que o Brasil, que $40 \%$ dos municípios não recebem nenhum serviço de coleta de lixo. 40 mil toneladas de lixo ficam sem coleta diariamente não reaproveitar o lixo que produz.. A coleta seletiva é praticada em pouco mais de 80 municípios brasileiros, basicamente nas regiões Sul e Sudeste do país

Figura 2 - Destino do lixo coletado no Brasil
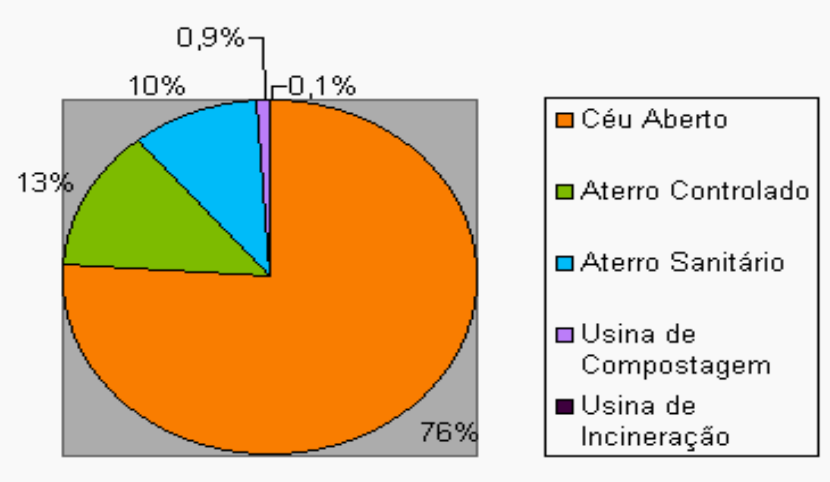

Fonte: Sanare - revista técnica da sanepar 
Figura 3 - Shopping Center Norte. O terreno está contaminado com gás metano e corre o risco de explosão. No local funcionava um lixão e com o tempo, o material orgânico jogado ali liberou o gás (metano) altamente explosivo.

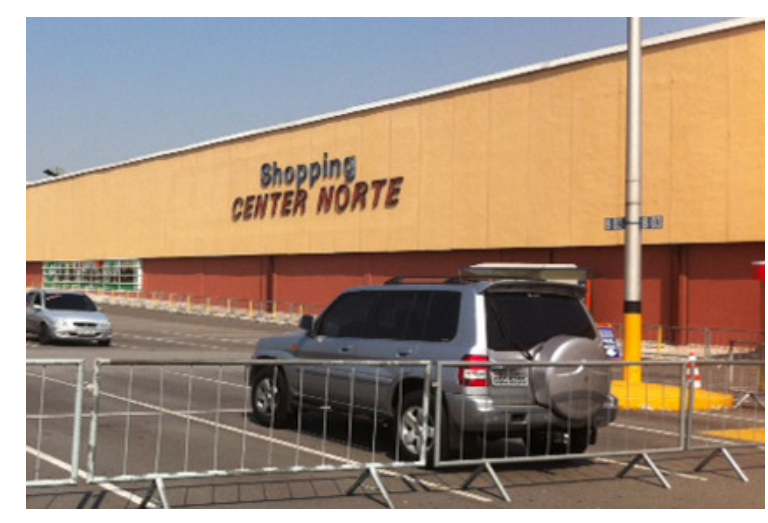

Fonte: Shopping Center Norte (Foto: Luciana Bonadio/G1)

Figura 3- lixão a céu aberto

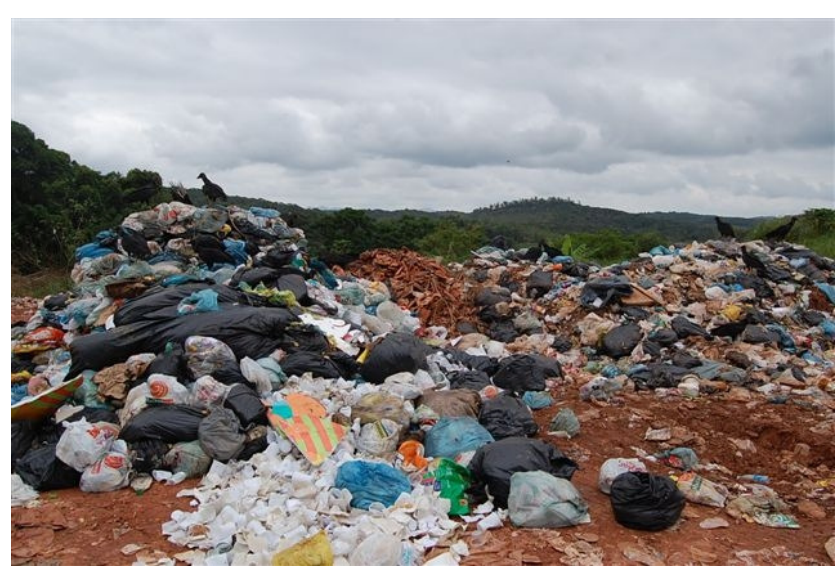

Fonte: WWW.valedoribeira.zip.net - acesso 17/11/2011 
Monografias Ambientais

$$
\text { (e-ISSN: 2236-1308) }
$$

\section{REMOANFSM}

Figura 4 - Moradores de rua vasculhando um lixão a céu aberto

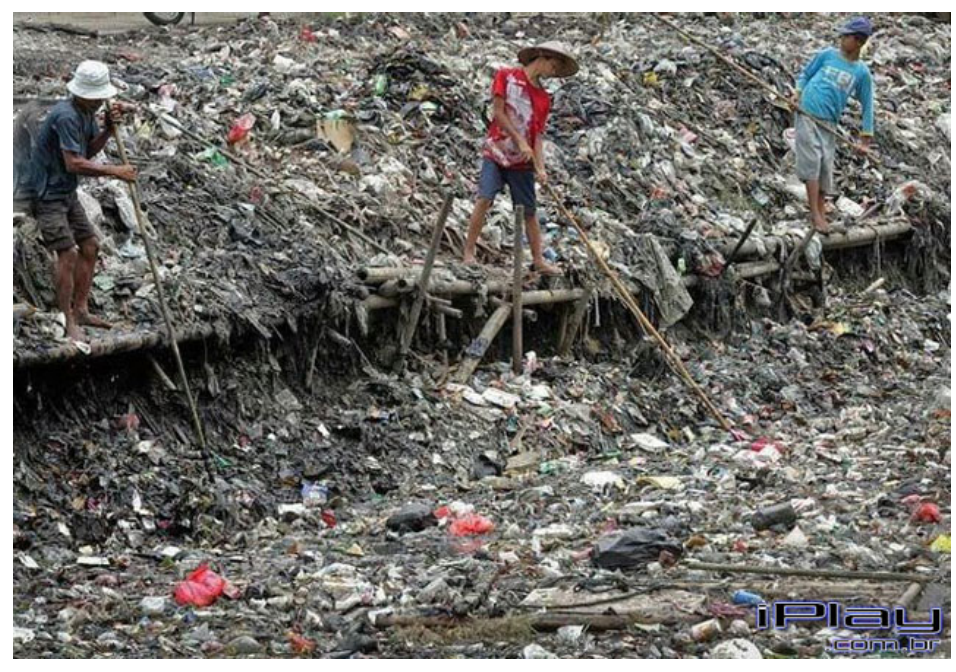

Fonte: www.iplay.com.br - acesso 17/11/2011

Figura 5 - ATERRO SANITÁRIO

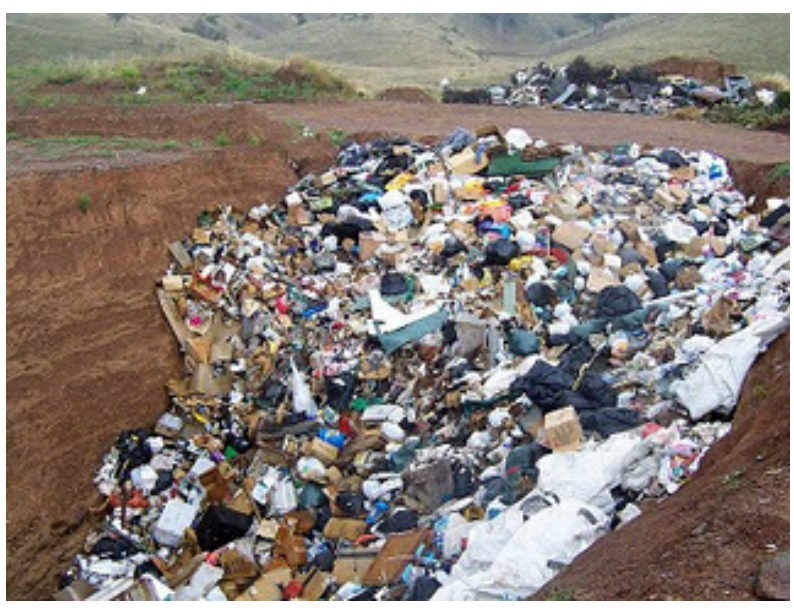

Fonte: WWW.brasilescola.com acessado 17/11/2011 
Figura 5 - Aterro Controlado

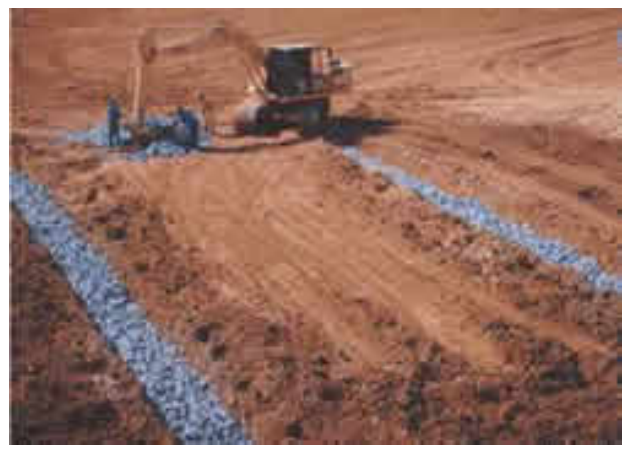

Fonte: WWW.portalsaofrancisco.com.br acesso 17/11/2011

\section{FIGURA 6 - ESQUEMÁTICA DE UM ATERRO CONTROLADO}

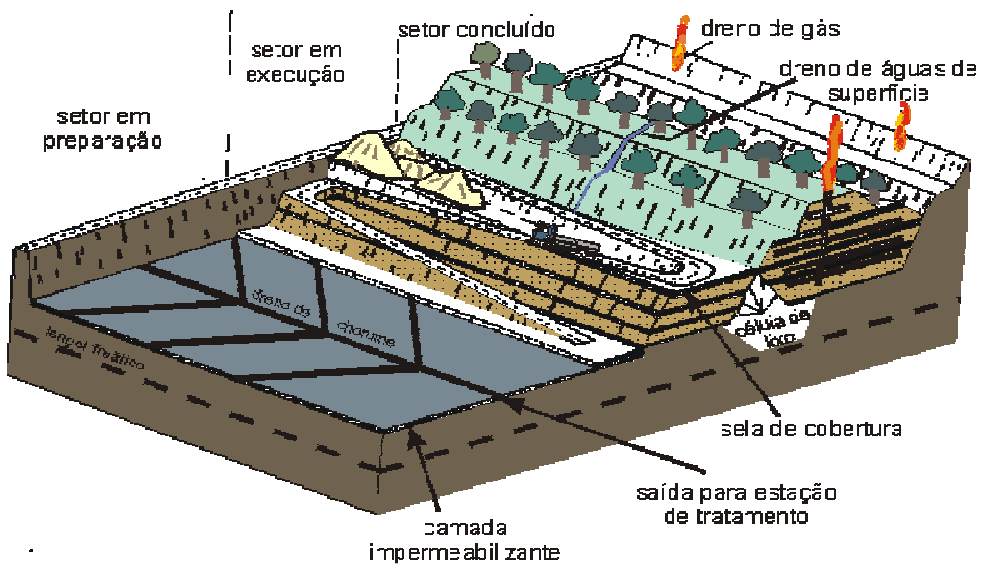

Fonte: WWW.portalsaofrancisco.com.br acesso 17/11/2011

\section{- Incineração}

Há muito tempo vinha se pensando em opções para diminuir o lixo, e foi projetado o incinerador, por Alfred Fryer, na Inglaterra. É um processo em que o lixo é seria queimado, reduzindo o peso e o volume, mas não seria o melhor método, traria prejuízos para a economia e a natureza, além do alto custo se a combustão for incompleta pode aparecer monóxido de carbono e partículas que acabam sendo lançados na atmosfera como fuligem ou negro fumo. Muitas substâncias são altamente tóxicas, poluindo rios, trazendo mau cheiro e a poluição visual. 
Monografias Ambientais

$$
\text { (e-ISSN: 2236-1308) }
$$

REMOANFSM

Figura 7 - Usina de Incineração

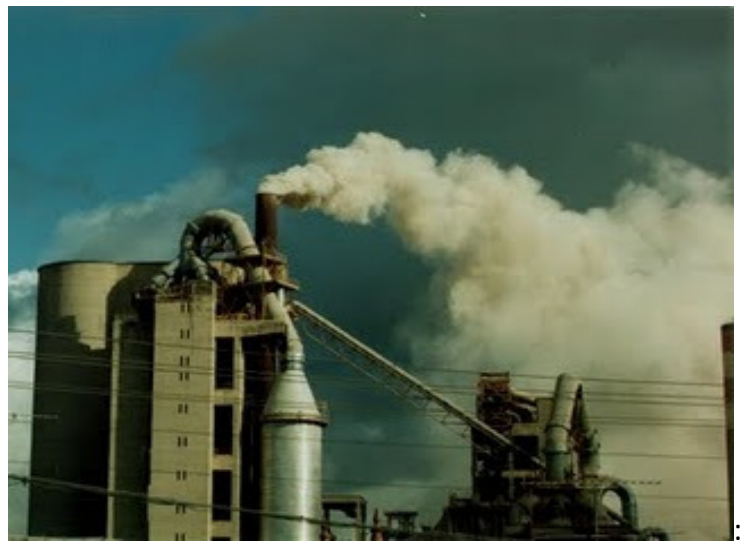

http://centrodeestudosambientais.wordpress.com - acesso 18/11/2011

Figura 8- Usina de Compostagem
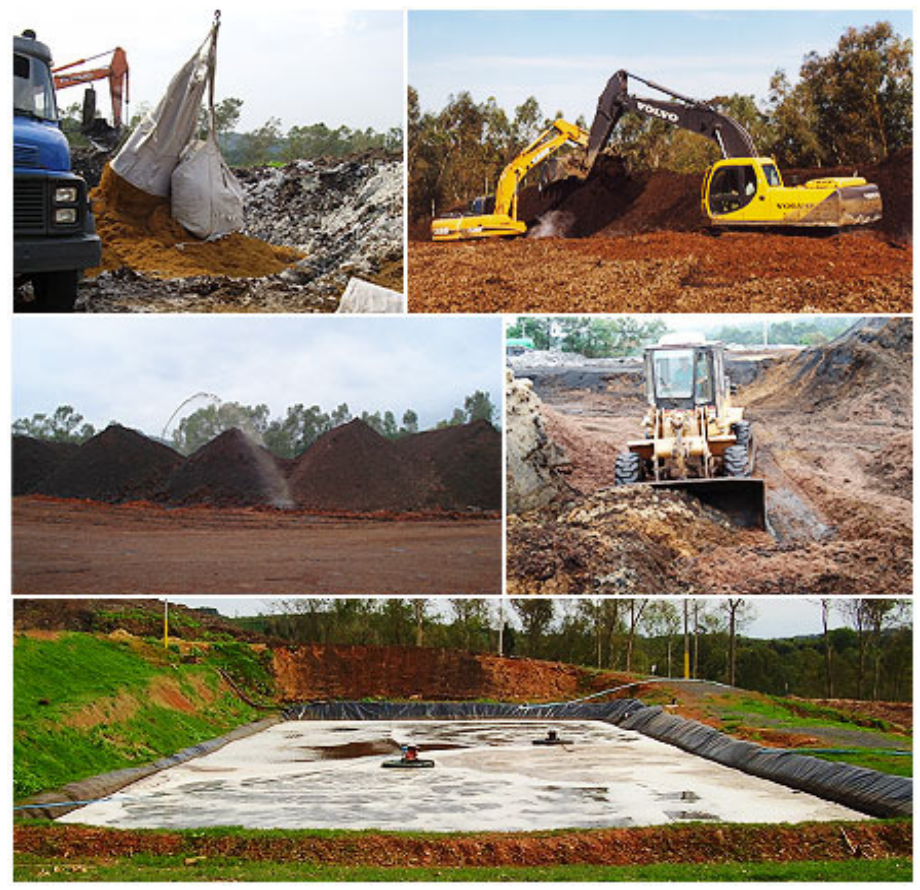

Fonte: WWW.ecocitrus.com.br acessado 18/11/2011

\section{Reciclagem no Brasil}

Uma nova opção de diminuir o lixo surge a partir da década de 1980, ficou conhecida com reciclagem (fazer reciclar) que significa transformar objetos materiais usados em novos 
produtos para o consumo. Esta necessidade foi despertada pelos seres humanos, que a partir do momento percebeu os benefícios que este procedimento trás para o planeta Terra. A importância e as vantagens processo de reciclagem, que além de preservar o meio ambiente também gera riquezas, os materiais mais reciclados são o vidro, o alumínio, o papel e o plástico. Esta reciclagem contribui para a diminuição significativa da poluição do solo, da água e do ar. Muitas indústrias estão reciclando materiais como uma forma de reduzir os custos de produção.

Figura 9. Símbolo Internacional da reciclagem

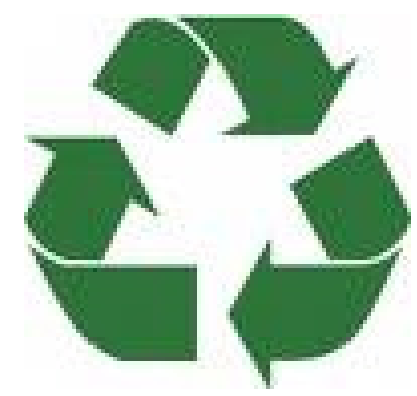

\section{Por que reciclar?}

Reciclar implica reaproveitar, reutilizar. A produção de materiais reciclados faz com que haja uma menor utilização dos recursos naturais da Terra, um menor consumo de energia, menos lixeiras e incineradoras e uma redução da poluição.

\section{Benefícios específicos da Reciclagem}

Conforme o Portal São Francisco e pesquisa realizada pela Pontifícia Universidade Católica do Paraná (PUCPR) demonstraram dados sobre benefícios da reciclagem.

\section{Papel}

- A cada 28 toneladas de papel reciclado evita-se o corte de 1 hectare de floresta (1 tonelada evita-se o corte de 30 ou mais árvores).

- 1 tonelada de papel novo precisa de 50 a 60 eucaliptos, 100 mil litros de água e $5 \mathrm{mil} \mathrm{kW} / \mathrm{h}$ de energia

- 1 tonelada de papel reciclado precisa de $1.200 \mathrm{Kg}$ de papel velho, 2 mil litros de água e 1.000 a $2.500 \mathrm{~kW} / \mathrm{h}$ de energia.

- Com a produção de papel reciclado evita-se a utilização de processos químicos evitando-se a poluição ambiental: reduzem em $74 \%$ os poluentes liberados no ar e em $35 \%$ os despejados na água.

- A reciclagem de uma tonelada de jornais evita a emissão de 2,5 toneladas de dióxido de carbono na atmosfera

- O papel jornal produzido a partir das aparas requer $25 \%$ a $60 \%$ menos energia elétrica que a necessária para obter papel da polpa da madeira. 0 papel feito com material reciclado 
reduz em $74 \%$ os poluentes liberados no ar e em $35 \%$ os despejados na água, além de reduzir a necessidade de derrubar árvores.

\section{Vidro}

- São 100\% reciclável, portanto não é lixo. $1 \mathrm{~kg}$ de vidro reciclado produz $1 \mathrm{~kg}$ de vidro novo.

- As propriedades do vidro se mantêm mesmo após sucessivos processos de reciclagem. Ao contrário do papel, que vai perdendo qualidade ao longo de algumas reciclagens.

- O vidro não pode ser degradado facilmente, então não deve ser despejado no solo.

- Para a produção de um material feito de vidro são necessários diversos recursos naturais: areia, barrilha, calcário, carbonato de sódio, cal, dolomita e feldspato,

- A temperatura para fundição é, em média, 1.500 ㄷ, necessitando muita energia e equipamentos especializados.

- A reciclagem do vidro requer menos temperatura para ser fundido, economizando aproximadamente $70 \%$ de energia e permitindo maior durabilidade dos fornos.

- Uma tonelada de vidro reciclado evita a extração de 1,3 toneladas de areia, economiza $22 \%$ no consumo de barrilha (material importado) e $50 \%$ no consumo de água.

\section{Plástico}

- É derivado do petróleo, recurso natural não renovável com previsão de esgotamento dentro de 40 anos.

- A sua reciclagem economiza até $90 \%$ de energia e gera mão-de-obra pela implantação de pequenas e médias indústrias.

- 100 toneladas de plástico reciclado evita a extração de 1 tonelada de petróleo.

\section{Metal}

- A matéria prima requer exploração, processos tecnológicos sofisticados e altos custos energético, econômico e ambiental.

- A reciclagem de uma tonelada de aço economiza $1.140 \mathrm{Kg}$ de minério de ferro, $155 \mathrm{Kg}$ de carvão e $18 \mathrm{Kg}$ de cal.

- Na reciclagem de uma tonelada de alumínio economiza-se 95\% de energia (são 17.600kWh para fabricar alumínio a partir de matéria prima virgem contra $750 \mathrm{kwh}$ a partir de alumínio reciclado), cinco toneladas de bauxita e evita-se a poluição causada pelo processo convencional: redução de $85 \%$ da poluição do ar e $76 \%$ do consumo de água.

- Uma tonelada de latinhas de alumínio se for recicladas, economizam $200 \mathrm{~m}^{3}$ de aterros sanitários.

- $64 \%$ das latas no Brasil (1,7 bilhão de unidades) são recicladas, superando os índices de países como o Japão, Inglaterra, Alemanha, Itália, Espanha e Portugal. Entretanto, este número pode chegar próximo a $100 \%$ dependendo de suas atitudes! 
Monografias Ambientais

QUADRO DE RECICLAGEM NO BRASIL

Quadro 1 - Comparativo de Reciclagem com outros países:

\begin{tabular}{|c|c|c|}
\hline Material & O Brasil recicla & Curiosidades \\
\hline Vidro & $5 \%$ das embalagens & O Japão recicla $55,5 \%$ \\
\hline Papel/Papelão & $36 \%$ & O Brasil importa apenas para reciclar \\
\hline Plástico/Filme (sacolas de supermercados) & $15 \%$ & Representa 3\% do lixo urbano nas capitais. \\
\hline PET (embalagens de refrigerantes) & $15 \%$ & O PET reciclado se transforma em fibras. \\
\hline Óleo & $18 \%$ & $\begin{array}{l}\text { Apenas } 1 \% \text { do óleo consumido no mundo é } \\
\text { reciclado. }\end{array}$ \\
\hline Latas de aço & $35 \%$ & $\begin{array}{l}\text { O Brasil importa latas usadas para a } \\
\text { reciclagem. }\end{array}$ \\
\hline Pneu & $10 \%$ & O Brasil exporta pneu para a reciclagem. \\
\hline Embalagens longa-vida & não há dados & $\begin{array}{l}\mathrm{Na} \text { incineração é considerada excelente } \\
\text { combustível }\end{array}$ \\
\hline
\end{tabular}

Fonte: Ambiente Brasil

Educação Ambiental, Meio ambiente e sustentabilidade

Figura 10

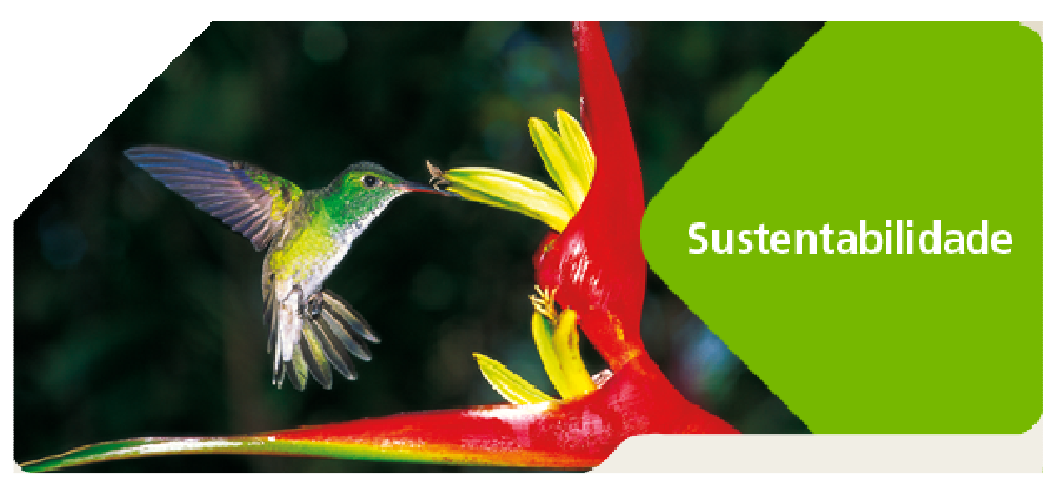

Fonte: http://verdedentro.wordpress.com/category/diversos/ acesso 27/11/2011

Dentro de minhas pesquisas, encontrei essa imagem lindíssima e esse poema que retrata bem nossos questionamentos sobre educação, meio ambiente e sustentabilidade decidi compartilhar 
com vocês, pois é de extrema beleza, o poema busquei a autoria e não localizei. Mesmo assim, decidi transcrevê-lo.

"Que mundo queremos deixar para os nossos descendentes Um mundo saudável

Um mundo de Paz e Harmonia

Precisamos cuidar de toda ecologia

Não apenas do sistema Natureza

Mas também de todas as manifestações de vibrações

De todos os reinos, matéria, sentidos, emoções e interações

Cabe ao Homem reger esta sinfonia

Guiado pela Fé, pela energia do Amor

Humildade, fraternidade e solidariedade

Para o bem das atuais e futuras humanidade

Dessa forma este Homem deve ser bem formado

Desde o ventre educados, conscientizados

Crianças, jovens de hoje serão lideres do amanha

Se não bem os formamos, por eles mesmos serão castigados

Estamos dando o valor necessário ao Ser?

Estamos colocando no devido lugar o Ter?

Nossas atitudes correspondem ao nosso discurso?

Nossos lideres, formadores de opinião agem com dignidade?

Será temerário se tudo isso não ocorrer?

Se o interesse prevalecer sobre o ideal?

Se a razão não ouvir o coração

O que será da sana educação?

É responsabilidade de toda sociedade

A Educação, não apenas sob a forma de instrução

mas também em todas suas manifestações

De maneira que nossa descendência herde essência

Um mundo melhor não significa apenas evoluir material e tecnicamente

Precisará sempre de seres melhores

Estamos numa fase de transição, com caminhos para o Bem ou para o Mal

Temos a obrigação de boas sementes cultivarem, de filhos educarem 
Para um mundo melhor para eles mesmos formar

"Eduque as crianças, para não precisar castigar os adultos"

Seja pelas leis sociais, seja pelas leis da Natureza, da ecologia total

Respeitando a interatividade e as leis de Deus.

Por um mundo de beleza

Por um mundo de paz

Por um mundo igual

Por uma vida de solidariedade

Que assim seja para alcançarmos a Eternidade..." (Anônimo)

\section{CONSIDERAÇÕES FINAIS}

\footnotetext{
"Embora ninguém possa voltar atrás e fazer um novo começo, qualquer um pode começar agora e fazer um novo fim."

Chico Xavier
}

A grande importância do papel da educação é no processo de humanização do homem e de transformação social. A evolução da sociedade está ligada à evolução da educação. Desta forma, surge com a reflexão sobre a prática, pela necessidade de sistematizá-la e organizá-la em função de determinados fins e objetivos.

Não devemos pensar na educação como sendo apolítica, e a escola como um espaço neutro fora das divergências sociais. Esquecendo que a escola está inserida na sociedade e a comunidade se localizada no meio ambiente em que o sujeito vive.

A Educação ambiental abrange todo conhecimento sobre o ambiente, a fim de ajudar à sua preservação e utilização sustentável dos seus recursos

O ser humano, historicamente, em função de sua sobrevivência precisou transferir matéria e energia do ambiente natural para a sua vida diária. Entretanto, o acelerado processo de sua ação devastadora em relação a estes hábitos, vem suscitando questionamentos uma vez que coloca em risco o futuro do planeta e de sua própria espécie.

A Lei Federal n. 9.394 de 1996, trás a sistematização da questão ambiental para sala de aula. Com os PCN a educação ambiental e a sustentabilidade passam a fazer parte do cotidiano dos professores e alunos, obedecendo a Lei de Educação Ambiental e não faz parte de uma só disciplina, mas atingi todas elas.

Ao mesmo tempo a Educação Ambiental tem a chance de estar presente em todas as disciplinas, indisciplinaridade, mas não possui um "status" de ser uma disciplina única, sendo muitas vezes deixada em segundo plano em relação aos conteúdos disciplinares.

A conscientização ambiental, só será possível com percepção e entendimento do real valor do meio ambiente natural em nossas vidas. O meio ambiente natural é o fundamento invisível das diferenças sócio econômicas entre países desenvolvidos e em desenvolvimento.

O dia em que cada brasileiro entender como esta questão afeta sua vida de forma direta e irreversível, o meio ambiente não precisará mais de defensores. A sociedade já terá entendido que preservar o meio ambiente é preservar a sua própria espécie, e fragilizar o meio ambiente, é fragilizar a economia, o emprego, a saúde, e tudo mais.

Esta falta de entendimento compromete a adequada utilização de nossa maior vantagem competitiva frente ao mundo: recursos hídricos, matriz energética limpa e renovável, 
biodiversidade, a maior floresta do mundo, e tantas outras vantagens ambientais que nós brasileiros temos e que atrai o olhar do mundo. E isso só será possível se haver uma maior conscientização através da informação e da educação.

\section{REFERÊNCIAS}

BRASIL. Secretaria de Educação Fundamental. Parâmetros curriculares nacionais: meio ambiente. Brasília: MEC/SEF, 1997c.

CARVALHO ISABELC. M. - Educação Ambiental - A formação do sujeito ecológico, Cortez 2006 São Paulo

Das concepções às práticas: educação ambiental, meio ambiente e qualidade de vida no ensino fundamental. 2005. (Mestrado em Educação Escolar) - Universidade Estadual Paulista

EFFTING, Tânia Regina. Educação Ambiental nas Escolas Públicas: Realidade e

Desafios. Marechal Cândido Rondon, 2007

FREIRE, Paulo. Pedagogia da Autonomia: saberes necessários à prática educativa.

São Paulo: Paz e Terra - 43o Edição - 2011

FREIRE, Paulo. Pedagogia da indignação: cartas pedagógicas e outros escritos.

LDB - LEI DE DIRETRIZES E BASES DA EDUCAÇÃO NACIONAL 9394/96

MARTINES JÚNIOR, Eduardo. Educação, cidadania e Ministério Público: o artigo 205 da Constituição e sua abrangência. 446 p. Tese (Doutorado em Direito Constitucional) - Pontifícia Universidade Católica de São Paulo. - 2006

PEREIRA, Valmir. A concepção de indivíduo nos parâmetros curriculares nacionais do ensino médio, 2007.

SILVA, MARINA - Ex-Ministra DO MEIO AMBIENTE

Ministério do Meio Ambiente - MMA

Centro de Informação, Documentação Ambiental e Editoração

http://www.mma.gov.br/port/sdi/ea/og/pog/arqs/livro ieab.pdf

http://www.pucpr.br, acesso em 17/11/2011.

http://verdedentro.wordpress.com/category/diversos/ acesso 27/11/2011

http://centrodeestudosambientais.wordpress.com, acesso 22/11/2011

http://www.portalsaofrancisco.com.br, acesso em 17/11/2011.

http://WWW.ecocitrus.com.br , acessado 18/11/2011 